\title{
Integração de clientes no processo de desenvolvimento de produtos: estudo de casos em empresas de bens de capital
}

\section{Customer integration in product development process: case study in capital goods companies}

\author{
Mario Orestes Aguirre González ${ }^{1}$ \\ José Carlos de Toledo² \\ Pedro Carlos Oprime ${ }^{2}$
}

\begin{abstract}
Resumo: Entender as necessidades atuais e futuras dos clientes, traduzi-las em requisitos do produto e incorporá-las no projeto do novo produto são atividades consideradas críticas para o sucesso do processo de desenvolvimento de produtos. Diversas estratégias são adotadas com a finalidade das empresas obterem maior eficiência e eficácia no processo de desenvolvimento de novos produtos, dentre elas destaca-se a integração de clientes neste processo. Este artigo tem por objetivo identificar, em uma amostra de empresas da indústria de bens de capital, as práticas adotadas para integração de clientes, comparar essas práticas com as recomendações da bibliografia e apresentar sugestões para a gestão dessa integração. Foram realizados estudos de casos em cinco empresas industriais do setor de bens de capital. As empresas desse setor, por desenvolverem produtos que, de modo geral, serão implantados nos processos de seus clientes, em princípio necessitam de uma maior integração com os clientes. A análise da revisão bibliográfica sobre o tema e dos resultados do estudo de casos, aponta que práticas de integração de clientes têm efeitos positivos no desempenho do processo de desenvolvimento de produto. Por outro lado, observa-se, nessas empresas, a necessidade de um maior grau de formalização dessas práticas, com adoção de procedimentos e técnicas de suporte. Assim, são propostas um grupo de considerações e recomendações para um melhor gerenciamento da integração de clientes no processo de desenvolvimento de produto.

Palavras-chave: Desenvolvimento de produto. Integração do cliente. Setor de bens de capital. Atividades de integração de clientes.
\end{abstract}

\begin{abstract}
Understanding current and future customer needs, translating them into product requirements, and incorporating them into new product design are activities considered critical to the success of product development processes. Several strategies are adopted by companies in order to achieve greater efficiency and effectiveness in the development of new products. Among them is customer integration into this process. This article aims to identify in a sample of capital good firms the practices adopted for customer integration, compare these practices with those suggested in the literature, and propose suggestions for managing this integration. Case studies were conducted in five manufacturing companies in the sector of capital goods. Since they develop products that are generally implemented in the processes of their clients, companies in this sector require greater customer integration. The analysis of the literature review on the subject and findings of the case studies indicate that customer integration practices have positive effects on the performance of the product development process. On the other hand, it was observed that these companies need a greater degree of formalization of these practices by adopting standard procedures and support techniques. Therefore, a set of recommendations and considerations were proposed for a better management of these customer integration practices in product development processes.
\end{abstract}

Keywords: Product development. Customer integration. Capital goods companies. Customer integration activities.

\footnotetext{
${ }^{1}$ Universidade Federal do Rio Grande do Norte - UFRN, Campus Universitário Lagoa Nova, CEP 59072-970, Natal, RN, Brasil, e-mail: mario@ct.ufrn.br

${ }^{2}$ Universidade Federal de São Carlos - UFSCar, Rod. Washington Luís, Km 235, SP 310, CEP 13565-905, São Carlos, SP, Brasil, e-mail: toledo@dep.ufscar.br; pedro@dep.ufscar.br
} 


\section{Introdução}

Vantagem competitiva, crescimento econômico e lucratividade das empresas são alguns dos resultados potenciais de atividades bem sucedidas de desenvolvimento de novos produtos (KOTLER, 2000; COOPER, 2001; DRUCKER, 2002; CHRISTENSEN; RAYNOR, 2003; MORGAN; LIKERT, 2006; ULRICH; EPPINGER, 2008; GRIFFIN et al., 2009).

Nas últimas décadas, o desenvolvimento de produtos tornou-se tema de maior interesse tanto na comunidade acadêmica como na comunidade empresarial. Embora na bibliografia da área sejam apresentados casos de sucesso sobre desenvolvimento de novos produtos, como, por exemplo, os casos da 3M (VON HIPPEL, 2001) e da Procter \& Gamble (ALAM, 2005; HUSTON; SAKKAB, 2006), também são apresentados dados sobre falhas dessas atividades, expressas em baixos índices de sucesso no lançamento de novos produtos no mercado (COOPER, 2001; STEVENS; BURLEY, 2003).

Page (1993), em um estudo com 171 empresas localizadas nos Estados Unidos, observou que a taxa de falha no lançamento de novos produtos era superior a $40 \%$, e esse índice seria maior e cresceria para projetos com maiores níveis de investimento e riscos. Cooper (2001), em um estudo com 122 empresas industriais americanas, observou que do total de novos produtos lançados no mercado, entre 35\% a $40 \%$ são retirados do mercado em um curto período de tempo após o lançamento. Stevens e Burley (2003), em um estudo com 360 empresas industriais localizadas na Holanda, Estados Unidos e Reino Unido, observaram que o índice de insucesso de novos produtos oscilava entre $40 \%$ e $54 \%$.

A busca de conhecimento sobre as causas desse insucesso conduziu ao aprofundamento de estudos sobre a gestão do processo de desenvolvimento de produto (COOPER, 2005). Uma linha de pesquisa na área de gestão do desenvolvimento de produto é a identificação de fatores críticos de sucesso, ou seja, práticas associadas ao desenvolvimento de produtos que, quando bem aplicadas, contribuem para melhorar o desempenho de novos produtos no mercado.

Dentre os fatores críticos, ressaltam-se a relevância do fator mercado, especificamente a compreensão das necessidades dos clientes-alvo e a incorporação do atendimento a essas necessidades no projeto do produto (GRIFFIN, 2005; KAHN, 2005; COOPER, 2007). Esse entendimento das necessidades do cliente é importante particularmente no início do processo de desenvolvimento do produto (PDP), quando os requisitos básicos do produto e do projeto são definidos e planejados. Assim, se as necessidades dos clientes não forem adequadamente compreendidas no início do PDP, isso conduz a retrabalhos no projeto ou até ao insucesso do produto no mercado.
Blackbourn, Scudder e Van Wassenhove (2000) constataram que investir mais tempo e esforço no entendimento das necessidades dos clientes de um projeto de software conduz a um menor tempo total do desenvolvimento e a uma maior produtividade das equipes de projeto. Gupta e Wilemon (1996), numa pesquisa com diretores de $P \& D$, constataram uma importante habilidade do gestor de P\&D que é a de "captar e entender as necessidades dos clientes", seguida pelos fatores "mapear o desenvolvimento da tecnologia" e "formar equipes multidisciplinares para os projetos".

Esses resultados de desempenho e constatações de algumas boas práticas têm direcionado as empresas a desenvolverem e implementarem processos organizacionais que possibilitem a obtenção de informações sobre as necessidades dos cliente e sua integração no projeto de novos produtos.

Segundo Von Hippel (2001), para solucionar um problema na inovação de produtos, devem-se juntar, virtualmente ou fisicamente, em um único lugar, as informações necessárias e a capacidade de resolver o problema. De maneira geral, a empresa fornecedora dos produtos tem a capacidade de resolver o problema e o cliente tem a informação sobre as suas necessidades, ainda que estas possam não estar claramente definidas (PRAHALAD; RAMASWAMY, 2000; JEPPESEN, 2005). Observa-se, assim, a necessidade e relevância da integração do cliente (IC) no processo de desenvolvimento de produto do fornecedor.

O objetivo deste artigo é propor considerações e sugestões que as empresas poderiam adotar para o gerenciamento das atividades de integração de clientes no PDP, a partir de revisão bibliográfica e de cinco estudos de caso realizados no setor de bens de capital. Esse setor é relevante para esse tipo de estudo, uma vez que as inovações de produtos se dão com alta influência e participação dos clientes como fonte de informação externa. Segundo a Pesquisa de Inovação Tecnológica (PINTEC), conforme IBGE (INSTITUTO ... 2007; 2010), sobre as atividades de inovação das empresas brasileiras entre os anos de 2003 a 2005 e de 2006 a 2008, nas empresas do setor de máquinas e equipamentos os clientes representam a principal fonte de informação para desenvolvimento de novos produtos.

\section{Integração de clientes no processo de desenvolvimento de produtos}

O processo de desenvolvimento de produto é considerado um dos principais processos de negócio da empresa e situa-se na interface entre a empresa e o mercado, cabendo a ele identificar, e mesmo se antecipar, as necessidades do mercado e propor 
soluções, por meio de projetos de novos produtos e de serviços que atendam tais necessidades.

A estrutura para o PDP, proposta por Rozenfeld et al. (2006), divide o processo de desenvolvimento de produtos em três macrofases (pré-desenvolvimento, desenvolvimento e pós-desenvolvimento). As macrofases de Pré e Pós-desenvolvimento são genéricas e podem ser aplicadas, com pequenas alterações, em todo tipo de empresa. Já a macrofase de Desenvolvimento enfatiza os aspectos tecnológicos correspondentes à definição do produto em si, suas características intrínsecas e forma de produção, devendo ser adaptada à realidade de cada projeto, da empresa e do setor industrial.

A integração de clientes no PDP, considerada neste trabalho, envolve um conjunto de atividades e decisões. Nesse sentido, a partir do trabalho de González e Toledo (2012), de revisão bibliográfica sistemática sobre Integração de Clientes, a qual analisou 72 artigos, este item do artigo foi estruturado em: fundamentos para a integração de clientes; critérios para escolha de clientes a serem integrados; tipos de interação com clientes; técnicas e ferramentas de apoio à integração entre empresa e clientes; e benefícios da IC no PDP.

\subsection{Fundamentos para integração de clientes no PDP}

O sucesso comercial de um novo produto depende de muitos fatores, sendo um dos principais a sua aceitação no mercado (PRAHALAD; RAMASWAMY, 2000; COOPER, 2005; GRIFFIN et al., 2009). Aumentar a probabilidade de aceitação do novo produto no mercado exige a realização de atividades específicas durante o PDP, principalmente pesquisas de mercado, com a finalidade de entender as reais necessidades dos clientes. Na maioria das vezes, essas necessidades estão implícitas, o que torna complexo identificá-las claramente. Dessa forma, algumas empresas utilizam práticas como observação do comportamento do cliente no seu ambiente de trabalho e realização de entrevistas aprofundadas com a finalidade de entender essas necessidades. Outras procuram integrar o cliente nas fases iniciais do PDP para melhor captarem as necessidades do mercado. Como consequência, um dos principais fundamentos para a IC no PDP é o conhecimento que os clientes detêm sobre as necessidades do mercado, sejam elas implícitas ou explícitas.

Outro fundamento é o conhecimento técnico que determinados clientes possuem, especialmente em contexto de negócios B2B - Business to Business (GRUNER; HOMBURG, 2000; VON HIPPEL, 2005; LETTL, 2007). Em determinados setores industriais, como o caso dos fabricantes de chips, de equipamentos médicos e de instrumentos de laboratório, os clientes, além de possuírem necessidades de novos equipamentos ou de melhorias nos equipamentos existentes, possuem conhecimentos técnicos e podem contribuir no projeto do novo produto. Para o desenvolvimento de equipamentos médicos, que envolve conhecimento tecnológico e conhecimento específico de profissionais da área de saúde, os médicos, como clientes, podem contribuir no desenvolvimento de novos produtos (LETTL, 2007; GONZÁLEZ et al., 2008).

Com o avanço das tecnologias da informação e com o maior nível de profissionalismo dos clientes, relacionados ao seu conhecimento e formação, cada vez mais eles detêm conhecimentos tecnológicos e sobre o mercado. Gassmann et al. (2005), Lagrosen (2005), Shah e Robinson (2006) e Raash, Herstatt e Loock (2008) consideram que a participação dos clientes tem influência positiva no desempenho de projetos de novos produtos, não somente pelo conhecimento sobre o mercado, mas também com o aporte de conhecimento técnico.

Do ponto de vista do marketing, outro fundamento se refere aos benefícios do relacionamento que a empresa estabelece com seus clientes, ao envolvê-los em projetos de novos produtos. Segundo Gruner e Homburg (2000), o relacionamento com os clientes por meio de canais de ouvidoria para sugestões e reclamações, entrevistas e consideração de suas ideias contribui para consolidar neles uma posição (status) de importância e que se traduz em satisfação e lealdade com a empresa. É o tipo de lealdade que se consegue quando o cliente é um admirador, isto é, considera-se parte da empresa (FRANKE; KEINZ; SCHREIER, 2008).

Assim, os três fundamentos básicos para IC no PDP são: conhecimento das necessidades do mercado, conhecimento técnico sobre o produto e manutenção de um bom relacionamento com os clientes.

\subsection{Critérios para seleção de clientes}

A seleção de clientes é um fator importante para o sucesso da IC. Para Alam (2005), existem três critérios que deveriam ser considerados durante a seleção de clientes para participação em projetos de novos produtos.

O primeiro dos critérios indica que uma empresa pode optar por escolher clientes com os quais já mantenha uma relação histórica de parceria devido à confidencialidade de informações envolvidas no desenvolvimento de um novo produto. Um gerente de produto necessita confiar nos clientes parceiros para manter sigilo sobre as informações consideradas críticas e confidenciais. Um cliente parceiro também necessita mostrar seu compromisso em realizar com eficiência as atividades de sua responsabilidade no PDP.

$\mathrm{O}$ segundo critério se refere à capacidade inovadora de certos clientes, tal característica pode ser captada 
pela empresa de diferentes formas: discussão informal acerca das necessidades de mercado entre clientes e a equipe de projeto; análise das reclamações dos clientes sobre produtos existentes; e discussão de ideias de novos produtos com o pessoal de vendas. Alam (2005) cita uma empresa que introduziu no mercado um cortador de grama que funciona à bateria e não precisa de uma pessoa para manipular. A empresa obteve a ideia e o apoio técnico quando um cliente de terceira idade reclamou sobre quão extenuante era cortar a grama com uma máquina manual e desejava um produto que fizesse o trabalho automaticamente, porém que deveria ter menos custos que os cortadores de grama tradicionais. Em geral, clientes que geram ideias de inovações tendem a conhecer o que propõem e podem articular de forma clara suas necessidades e planos (VON HIPPEL, 2005).

$\mathrm{O}$ terceiro critério indica que os clientes chamados de Usuários Líderes são a principal fonte de oportunidades para o desenvolvimento de novos produtos inovadores e lucrativos. O estudo de Von Hippel (1986) tornou-se referência na utilização desse critério de seleção de clientes. $\mathrm{O}$ autor distingue os clientes em comuns e Usuários Líderes. Os Usuários Líderes têm duas características: 1) apresentam necessidades atuais que se tornarão, no futuro, gerais no mercado; e 2) eles esperam se beneficiar substancialmente na obtenção de uma solução para suas necessidades.

Bonner e Walker (2004) e Kristensson, Gustafsson e Archer (2004) propõem que, para otimizar a participação do cliente nas atividades do PDP, os fabricantes devem conhecer a representatividade do cliente no mercado, seu esforço inovador, sua disponibilidade para cooperar e sua capacidade em manter sigilo acerca das informações.

Podem-se resumir os critérios de seleção dos clientes em: clientes parceiros; clientes com características de usuários líderes; com alto potencial de demanda; com competência técnica e inovadora; com disponibilidade para participar no projeto; com disponibilidade para divulgar o produto; com competência para testar o novo produto; e cliente formador de opinião.

\subsection{Tipos de interação entre empresa e seus clientes}

Dependendo do tipo de projeto, do perfil do cliente e da fase do processo de desenvolvimento do produto, a interação entre a empresa e seus clientes poderá ser de diferentes tipos (EDVARDSSON et al., 2006). Para isso, a infraestrutura oferecida pela empresa fabricante para as atividades de participação do cliente se torna fundamental, desde a disponibilidade de ambientes físicos até o uso de ambientes virtuais para a efetivação da interação.
Alam (2005) realizou um levantamento sobre as formas de interação entre uma empresa fabricante e seus clientes nas atividades consideradas importantes para o PDP, descritas a seguir:

- Entrevistas em profundidade: entrevistas com os clientes podem ser utilizadas para obter informações dos clientes e traduzi-las em requisitos para novos produtos e serviços (GRIFFIN; HAUSER, 1993). Alam (2005) cita a Gillette como exemplo de empresa com prática desse tipo de interação com seus clientes no PDP, especificamente no modelo de barbeador Mach3. Para o autor, esse tipo de interação trouxe ganhos no que se refere ao levantamento de novos conceitos de produtos e ideias para novos produtos complementares;

- Atividades em Grupos focados e brainstorming: para levantar informação de uma base ampla de clientes, uma empresa pode interagir por meio de reuniões de grupos focados ou sessões de brainstorming. A principal vantagem dos grupos focados e do brainstorming é que a dinâmica de grupo cumpre um papel fundamental na geração de informações úteis para novos produtos. Segundo Alam (2005), a prática desse tipo de interação é bastante difundida, citando como exemplo a Procter \& Gamble no desenvolvimento de seu modelo Crest SpinBrush;

- Integração do cliente na equipe de projeto: representantes dos clientes podem ser incorporados à equipe de projeto e fornecer informações em várias fases do PDP. A presença de clientes na equipe de projeto possibilita, segundo Alam (2005), a transformação do conhecimento implícito das necessidades de mercado em conhecimento explícito e fornece uma melhor perspectiva para as decisões do PDP. Os clientes também podem ajudar na dissolução dos conflitos interfuncionais dentro da empresa, por expressarem suas perspectivas exclusivas e únicas. De acordo com Beets (1994) apud Alam (2005), a Boeing, quando desenvolveu seu modelo de avião 777 , formou sua equipe de desenvolvimento incluindo engenheiros de três companhias aéreas clientes. Um desses clientes, a British Airways, sugeriu mais de 100 mudanças para o modelo de avião 777, sendo a maioria delas incluídas no projeto final;

- Atividades em Painéis de clientes: a empresa fabricante pode identificar clientes seletos para fazerem parte de um painel de clientes e, periodicamente, participar em várias fases do 
PDP. Segundo Digman (2002), o fabricante de jeans Levi formou um painel de consumidores jovens nas principais cidades europeias, como Milão, Paris, Londres, e solicitou que descrevessem as situações de uso do produto e as últimas tendências. Como resultado, informações valiosas foram captadas para sua coleção Engineered Jeans. Outro exemplo desse tipo de interação, conforme destaca Mascarenhas, Kesavan e Bernacchi (2004), foi o utilizado na Volvo ao desenvolver seu modelo X90;

- Observação de clientes: uma empresa pode obter ideias e informações sobre novos produtos por simplesmente observar como os clientes utilizam o produto. Deschamps e Nayak (1997) apresentam vários exemplos de empresas de vanguarda que observam ativamente seus clientes para obterem informações de entrada para seus projetos de desenvolvimento de novos produtos. Alam (2005) cita que a empresa Bosch, fabricante de ferramentas elétricas, solicita de seus clientes no momento da compra, a permissão para lhes fazer uma visita em suas residências, para observar como utilizam seu produto;

- Reuniões informais: ao invés de encontros prolongados, uma empresa fabricante pode ocasionalmente organizar encontros informais e se engajar em diálogos referentes a novos produtos com os principais clientes. Exemplo desses encontros informais são almoços e jantares, nos quais desenvolvedores e clientes interagem informalmente. Alam (2005) cita uma empresa fabricante de produtos de aço que periodicamente convida seus clientes, fabricantes de equipamentos de construção, a almoços para discutirem suas necessidades, mostrando a eles especificações de projeto e de produtos que estão sendo desenvolvidos;

- Visita a clientes: gerentes de produtos podem visitar seus clientes regularmente para discutirem oportunidades de novos produtos. Deschamps e Nayak (1997) citam a maior fabricante americana de embalagens Signode Corporation, a qual capacita suas equipes de projeto para visitarem seus principais clientes com a finalidade de pesquisar sobre oportunidades de novos produtos; e

- Interação baseada na internet: a internet cumpre um importante papel na interação entre fabricante e seus clientes. Segundo Ozer (2003), a Polaroid utilizou a internet para obter participação do cliente para desenvolver seu produto I-Zone - uma câmera de bolso de revelação instantânea. A
Polaroid criou uma página na web e solicitou a seus clientes potenciais que visitassem a página e montassem uma câmera ideal com os atributos preferidos. Os resultados dessa atividade de interação foram surpreendentes para a equipe de $P \& D$, uma vez que os clientes achavam que o produto deveria ser mais divertido e agradável (o oposto do produto dos engenheiros da Polaroid), pois consideravam que o produto deveria ter mais avanço tecnológico, ser da moda e caro (OZER, 2003). Também a BMW criou uma página na web, denominada "Virtual Innovation Agency”, para interagir com seus clientes. Pessoas apaixonadas por carros podem discutir on-line na web para compartilhar ideias de inovação com outros usuários e com os funcionários da BMW. Esse meio de interação tem como benefício o baixo custo e a abrangência de uma maior quantidade de clientes participantes. Outro exemplo é da Procter \& Gamble que, no Reino Unido, formou uma comunidade para novos produtos; trata-se de um clube de clientes que se encontram num website e discutem ideias de novos produtos. A Procter \& Gamble, conforme ressalta Alam (2005), obteve alta participação de clientes no desenvolvimento de seu produto "Sunny Deligth".

Outros tipos de interação incluem: intercambio de e-mails (ROWLEY; KUPIEC-TEAHAN; LEEMING, 2007); entrevistas individuais (PALS et al., 2008); entrevistas em grupo (GRIFFIN; HAUSSER, 1993); testes de protótipos em conjunto (SHAH; ROBINSON, 2006); reuniões virtuais (DAHAN; HAUSSER, 2002; KIM; BAE; KANG, 2008); e reuniões presenciais (HEISKANEN et al., 2007).

\subsection{Técnicas e ferramentas de apoio à integração de clientes}

Sandén (2007) afirma que as técnicas de IC são os meios pelos quais as informações dos clientes são coletadas, possibilitando a interação entre clientes e seu fornecedor e a geração do conhecimento desejado.

De acordo com Frank e Piller (2004), as técnicas utilizadas para a IC provêm das técnicas de pesquisa de mercado. Entretanto, segundo a conveniência e objetivo da pesquisa com clientes, essas técnicas podem ser classificadas em técnicas que excluem o cliente e técnicas que incluem o cliente. A lógica dessa classificação é que clientes sejam incluídos se eles são a principal fonte de informação coletada e excluídos se não o são. Em consequência, todas as técnicas que coletam dados primários dos clientes podem ser caracterizadas como técnicas de integração do cliente. 
Outros autores como Janssen e Dankbaar (2008) classificam as técnicas em tradicionais e modernas. As técnicas tradicionais citadas incluem: survey, entrevistas, grupos focados, teste do conceito, teste beta, etc. Já as técnicas modernas envolvem: Usuários Líderes, Delphi, ferramentas (toolkits) para inovação e comunidade virtual de usuários.

No Quadro 1, são apresentadas algumas técnicas do primeiro grupo (tradicionais) e do segundo grupo (modernas).

\subsection{Benefícios da IC no PDP}

Diversos ganhos podem ser obtidos com a IC no PDP. O Quadro 2 apresenta os tipos de benefícios potenciais, citados em artigos, que as empresas podem obter ao envolver os clientes em projetos de desenvolvimento de novos produtos.

Embora Beckers e Peters (1998) considerem como desvantagem da IC o risco de gerar conflitos entre a empresa fabricante e seus clientes, por questões de propriedade intelectual, Enkel, Kausch e Gassmann (2005) consideram que esse tipo de risco pode ser reduzido pela definição clara dos papéis e dos benefícios no início da relação e concluem que o risco de integrar clientes é menor em comparação ao risco da não integração.

\section{Método da pesquisa}

A pesquisa de campo realizada teve uma abordagem qualitativa pela necessidade de se aprofundar em conhecimentos sobre a prática da integração de clientes no PDP. Nessa abordagem, optou-se por estudo de casos, por permitir conhecer descrições empíricas de particularidades da ocorrência do fenômeno em estudo (YIN, 2001). O uso de um ou mais casos possibilita gerar conhecimentos em forma de proposições e teorias resultantes da análise da evidência empírica dos casos (EISENHARDT; GRAEBNER, 2007).

A pesquisa de campo ocorreu em dois momentos. No primeiro, foi realizada uma pesquisa em duas empresas. O objetivo foi conhecer, de forma exploratória, a prática da participação do cliente no desenvolvimento de produto. As entrevistas foram realizadas com os gerentes de desenvolvimento de produto das empresas.

No segundo momento, após a elaboração de uma estrutura conceitual para gestão da IC no PDP foi

Quadro 1. Técnicas e ferramentas de suporte à integração do cliente no PDP.

\begin{tabular}{|l|l|}
\hline \multicolumn{1}{|c|}{ Técnica } & \multicolumn{1}{c|}{ Objetivo } \\
\hline Grupos focados & Aplicação abrangente, entre elas, identificação de atributos para novos produtos. \\
\hline Teste Beta & Testar o produto no ambiente real. \\
\hline Teste do conceito & Testar conceitos potenciais de novos produtos. \\
\hline Método Delphi & Otimizar o processo de obtenção de opiniões de um grupo de clientes especialistas. \\
\hline Método Lead-user & Geração de conceitos de produtos inovadores. \\
\hline Toolkits para inovação & $\begin{array}{l}\text { Permite aos clientes criar e testar o desenho de produtos por meio de um } \\
\text { conjunto de ferramentas de design amigável ao usuário. }\end{array}$ \\
\hline Comunidade virtual de usuários & $\begin{array}{l}\text { Por meio da comunicação e interação entre os usuários se gera conhecimento } \\
\text { sobre os clientes, sobre suas necessidades e para futuros desenvolvimentos. }\end{array}$ \\
\hline
\end{tabular}

Quadro 2. Benefícios da integração do cliente no PDP.

\begin{tabular}{|l|l|}
\hline \multicolumn{1}{|c|}{ Benefícios } & \multicolumn{1}{c|}{ Principais artigos } \\
\hline Ideias para inovação radical & $\begin{array}{l}\text { Von Hippel (1986, 2001); Lilien et al; (2002); Magnusson (2003); } \\
\text { Kristensson, Gustafsson e Archer (2004); Matthing, Sandén e Edvardsson } \\
(2004) ; \text { Heiskanen et al; (2007); Lettl (2007); Shah e Robinson (2007); } \\
\text { Schreier e Prugl (2008). }\end{array}$ \\
\hline $\begin{array}{l}\text { Reduz incertezas e riscos dos novos } \\
\text { produtos }\end{array}$ & $\begin{array}{l}\text { Gales e Mansur-Cole (1995); Dahlsten (2004); Kristensson, Gustafsson } \\
\text { e Archer (2004); Matthing, Sandén e Edvardsson (2004); Enkel, } \\
\text { Kausch e Gassmann (2005); Enkel, Perez-Freije e Gassmann (2005); } \\
\text { Heiskanen et al; (2007); Schreier e Prugl (2008). }\end{array}$ \\
\hline Ideias para inovação incremental & Von Hippel (2001); Kujala (2003); Brockhoff (2003); Shah e Robinson (2007). \\
\hline Reduz o custo de desenvolvimento & Von Hippel e Katz (2002); Brockhoff (2003); Franke e Piller (2004). \\
\hline Aumenta o nível de parceria & Lau, Yam e Tan (2007); Shah e Robinson (2007); Schreier e Prugl (2008). \\
\hline $\begin{array}{l}\text { Aumenta a produtividade da equipe do } \\
\text { projeto }\end{array}$ & Von Hippel e Katz (2002); Chen e Yan (2008); Buur e Matthews (2008). \\
\hline Reduz o número de mudanças no projeto & Kujala (2003); Buur e Matthews (2008). \\
\hline
\end{tabular}


realizada a pesquisa de campo em cinco empresas. A escolha das empresas seguiu quatro critérios: as empresas deveriam ser líderes no segmento de mercado em que atuam; realizarem atividades de desenvolvimento de produto pelo menos há cinco anos; mostrar disponibilidade para participação na pesquisa; o conjunto das empresas escolhidas deveria abranger todos os grupos da divisão 28, Fabricação de Máquinas e Equipamentos, da CNAE - Classificação Nacional de Atividades Econômicas do IBGE - Instituto Brasileiro de Geografia e Estatística.

Para o primeiro critério, foi utilizada a base de dados da ABIMAQ - Associação Brasileira da Indústria de Máquinas e Equipamentos para conhecer o grupo de empresas que atendia essa condição, tendo-se encontrado um alto número de empresas (acima de 50) localizadas no Estado de São Paulo O segundo e terceiro critérios foram aplicados por meio de contato preliminar com as empresas para identificar se realizavam atividades do PDP. Com esses critérios, o número de empresas identificadas foi reduzido a 22.

Para o quarto critério, "inserção na divisão 28 - Fabricação de Máquinas e Equipamentos - do CNAE" chegou-se a seis grupos de empresas: fabricação de motores, bombas, compressores e equipamentos de transmissão, fabricação de máquinas e equipamentos de uso geral, fabricação de tratores e de máquinas e equipamentos para agricultura e pecuária, fabricação de máquinas-ferramenta, fabricação de máquinas e equipamentos de uso na extração mineral e na construção e fabricação de máquinas e equipamentos de uso industrial específico. As cinco empresas escolhidas, para o estudo, em conjunto, abrangem representantes desses seis grupos da divisão 28 do CNAE.

O perfil das empresas, mostrado no Quadro 3, indica que são exportadoras, sendo quatro de grande porte (pelo critério de faturamento) e uma de médio porte. Todas possuem certificação ISO 9001:2000.

As entrevistas foram realizadas com três representantes por empresa: o gerente de engenharia; o gerente de marketing; e o gerente de serviços e/ou de assistência técnica e/ou de qualidade. Foi utilizado como instrumento de pesquisa um roteiro de entrevistas, conforme apresentado no Apêndice. As entrevistas foram individuais e tiveram intervalo de tempo, entre as entrevistas com os diferentes representantes da empresa, maior do que 30 minutos, tempo necessário para a análise das respostas do entrevistado anterior e para revisar o plano de entrevista com o entrevistado seguinte.

A análise de informações de cada empresa pesquisada, a análise intracaso, foi realizada pela triangulação de informações da entrevista, de documentos repassados pelos entrevistados e da observação do pesquisador. Com as informações dos cinco casos, foi realizada a análise em conjunto (intercasos).

\section{Descrição e análise dos casos}

Nesta sessão, apresenta-se um resumo das informações levantadas e analisadas nas empresas, em relação aos temas relativos à integração de

Quadro 3. Características gerais das empresas.

\begin{tabular}{|c|c|c|c|c|c|}
\hline & Empresa A & Empresa B & Empresa C & Empresa D & Empresa E \\
\hline Produtos & $\begin{array}{l}\text { Máquinas e } \\
\text { equipamentos } \\
\text { para } \\
\text { processamento } \\
\text { de frutas } \\
\text { cítricas. }\end{array}$ & $\begin{array}{l}\text { Equipamentos de } \\
\text { cirurgia hospitalar; } \\
\text { Equipamentos de } \\
\text { lavanderia hospitalar; } \\
\text { Implantes ortopédicos } \\
\text { e ferramental. }\end{array}$ & $\begin{array}{l}\text { Máquinas- } \\
\text { ferramentas; } \\
\text { Injetoras de } \\
\text { plástico e } \\
\text { fundições; } \\
\text { Usinagem. }\end{array}$ & $\begin{array}{c}\text { Equipamentos } \\
\text { médico- hospitalares; } \\
\text { equipamentos/sistemas } \\
\text { para área militar; } \\
\text { equipamentos/sistemas } \\
\text { para a área espacial. }\end{array}$ & $\begin{array}{c}\text { Sistemas de } \\
\text { perfuração; } \\
\text { sistemas para } \\
\text { filtragem } \\
\text { industrial; } \\
\text { sistemas para } \\
\text { bombeamento. }\end{array}$ \\
\hline Porte & Grande porte & $\begin{array}{c}\text { Pelo número de } \\
\text { funcionários - empresa } \\
\text { de médio porte. Pelo } \\
\text { faturamento - empresa } \\
\text { de grande porte. }\end{array}$ & Grande porte & $\begin{array}{c}\text { Pelo número de } \\
\text { funcionários - empresa } \\
\text { de médio porte. Pelo } \\
\text { faturamento - empresa } \\
\text { de grande porte. }\end{array}$ & Médio porte \\
\hline Exportação & $\begin{array}{l}\text { América do } \\
\text { Sul e Estados } \\
\text { Unidos }\end{array}$ & $\begin{array}{l}\text { América do Sul, } \\
\text { América Central, } \\
\text { Portugal, Oriente } \\
\text { Médio e África. }\end{array}$ & $\begin{array}{c}\text { América do } \\
\text { Sul, América } \\
\text { Central, } \\
\text { América do } \\
\text { Norte, Oriente } \\
\text { Médio e África. }\end{array}$ & $\begin{array}{l}\text { América do Sul e } \\
\text { Estados Unidos }\end{array}$ & $\begin{array}{l}\text { América do } \\
\text { Sul e América } \\
\text { Central. }\end{array}$ \\
\hline $\begin{array}{l}\text { Certificações } \\
\text { e registros }\end{array}$ & $\begin{array}{c}\text { ISO } \\
\text { 9001:2000; } \\
\text { marca CE; } \\
\text { marca FDA. }\end{array}$ & $\begin{array}{l}\text { ISO 9001:2000; ISO } \\
\text { 13485:2003; Marca CE. }\end{array}$ & $\begin{array}{l}\text { ISO 9001:2000; } \\
\text { ISO/TS 16949; } \\
\text { ISO 14000; } \\
\text { Marca CE. }\end{array}$ & $\begin{array}{c}\text { ISO 9001:2000; ISO } \\
\text { 13485:2003; Marca } \\
\text { CE; Marca FDA. }\end{array}$ & $\begin{array}{c}\text { ISO } \\
9001: 2000 ; \\
\text { ISO } 14000 .\end{array}$ \\
\hline
\end{tabular}


clientes no PDP: gestão do PDP (modelo de gestão, tipos de projetos, estratégia de relacionamento com clientes e equipe); IC no PDP (critérios de escolha de clientes, tipos de interação, técnicas e ferramentas de apoio a IC); e benefícios obtidos pela IC no PDP.

\subsection{Características da gestão do PDP}

Os dados levantados nas empresas sobre sua gestão do PDP estão sintetizados no Quadro 4. As empresas utilizam modelos próprios para gerenciar suas atividades de desenvolvimento de novos produtos. As empresas A, B e C basearam seu modelo nas diretrizes da ISO 9001: 2000. Essa informação é corroborada por serem certificadas pela ISO 9001 cujo escopo inclui o projeto de novos produtos. A empresa $\mathrm{C}$ utiliza um modelo que teve como referência a ISO/TS 16949. Já a empresa D utiliza um modelo de gestão do PDP concebido no meio acadêmico e implantado na empresa há cerca de cinco anos.

Nesses modelos adotados, a inclusão de conhecimento sobre gestão de projetos está inserida pela consideração de conceitos do PMBOK nas empresas. Além disso, a empresa $\mathrm{C}$ tem inserido na gestão do PDP conceitos e princípios Seis Sigma.
Todas as empresas desenvolvem projetos de diferentes níveis de complexidade, desde projetos incrementais até projetos de produtos novos para o mercado.

Em todas as empresas, o projeto é conduzido por uma equipe constituída por funcionários de diferentes departamentos. Outra característica comum nessas empresas é a presença de um líder de equipe, sendo a liderança fixa ao longo de todo o processo de desenvolvimento.

\subsection{Características da integração de clientes no PDP}

Baseado no estudo de revisão bibliográfica sistemática de González (2010), a IC no PDP das empresas estudadas foi analisada nos seguintes aspectos: critérios para escolha de clientes, tipos de interação e técnicas e/ou ferramentas de apoio à IC no PDP. Essas características são apresentadas no Quadro 5.

Quanto ao reconhecimento das capacidades dos clientes para sua contribuição no PDP, todas as empresas concordam que os clientes possuem conhecimentos desejáveis sobre as necessidades do mercado. À exceção da empresa A, as demais também reconhecem que determinados clientes

Quadro 4. Características da gestão do PDP das empresas.

\begin{tabular}{|c|c|c|c|c|c|}
\hline & Empresa A & Empresa B & Empresa C & Empresa D & Empresa E \\
\hline $\begin{array}{c}\text { Modelo de } \\
\text { gestão do PDP }\end{array}$ & $\begin{array}{l}\text { Próprio, adotado } \\
\text { do modelo } \\
\text { ISO9000 e } \\
\text { PMBOK. }\end{array}$ & $\begin{array}{c}\text { Próprio, adotado } \\
\text { do modelo } \\
\text { ISO9000; ISO } \\
\text { 13485:2003 e } \\
\text { PMBOK. }\end{array}$ & $\begin{array}{l}\text { Próprio, adotado } \\
\text { do modelo ISO/TS } \\
\text { 16949, PMBOK } \\
\text { e princípios da } \\
\text { abordagem Seis } \\
\text { Sigma. }\end{array}$ & $\begin{array}{c}\text { Modelo de } \\
\text { referência próprio } \\
\text { com abordagem } \\
\text { de processo para } \\
\text { o PDP. }\end{array}$ & $\begin{array}{c}\text { Modelo } \\
\text { adaptado da } \\
\text { ISO 9000: } \\
2000 .\end{array}$ \\
\hline $\begin{array}{c}\text { Equipe de } \\
\text { Engenharia }\end{array}$ & $\begin{array}{l}17 \text { funcionários. } \\
\text { 35\% com } \\
\text { pós-graduação. }\end{array}$ & $\begin{array}{l}18 \text { funcionários. } \\
28 \% \text { com } \\
\text { pós-graduação. }\end{array}$ & $\begin{array}{l}95 \text { funcionários. } \\
25 \% \text { com } \\
\text { pós-graduação. }\end{array}$ & $\begin{array}{l}16 \text { funcionários. } \\
38 \% \text { com } \\
\text { pós-graduação. }\end{array}$ & $\begin{array}{l}11 \text { funcionários. } \\
36 \% \text { com } \\
\text { pós-graduação. }\end{array}$ \\
\hline $\begin{array}{l}\text { Tipos de } \\
\text { Projetos }\end{array}$ & $\begin{array}{l}\text { Incremental; novo } \\
\text { para a empresa; } \\
\text { e novo para o } \\
\text { mercado. }\end{array}$ & $\begin{array}{l}\text { Incremental; novo } \\
\text { para a empresa; } \\
\text { e novo para o } \\
\text { mercado. }\end{array}$ & $\begin{array}{l}\text { Incremental; novo } \\
\text { para a empresa; } \\
\text { e novo para o } \\
\text { mercado. }\end{array}$ & $\begin{array}{l}\text { Incremental; novo } \\
\text { para a empresa; } \\
\text { e novo para o } \\
\text { mercado. }\end{array}$ & $\begin{array}{l}\text { Incremental; } \\
\text { novo para o } \\
\text { mercado. }\end{array}$ \\
\hline $\begin{array}{l}\text { Estratégia de } \\
\text { relacionamento } \\
\text { com seus } \\
\text { clientes }\end{array}$ & $\begin{array}{c}\text { Visitas frequentes } \\
\text { da área comercial } \\
\text { aos clientes e } \\
\text { disponibilização } \\
\text { de seus } \\
\text { laboratórios de } \\
\text { pesquisa aos } \\
\text { clientes. }\end{array}$ & $\begin{array}{c}\text { Mantém } \\
\text { comunicação com } \\
\text { os clientes de sua } \\
\text { base de dados por } \\
\text { meio da internet, } \\
\text { fornecendo } \\
\text { informações } \\
\text { e notícias de } \\
\text { interesse. }\end{array}$ & $\begin{array}{l}\text { Fornece serviços } \\
\text { de pré-venda, } \\
\text { na forma de } \\
\text { consultoria } \\
\text { e serviço de } \\
\text { pós-venda com } \\
\text { funcionários da } \\
\text { própria empresa. }\end{array}$ & $\begin{array}{c}\text { Mantém } \\
\text { comunicação com } \\
\text { os clientes de sua } \\
\text { base de dados por } \\
\text { meio da internet } \\
\text { fornecendo } \\
\text { informações } \\
\text { e notícias } \\
\text { de interesse. } \\
\text { Participação como } \\
\text { patrocinadora de } \\
\text { eventos e cursos } \\
\text { de capacitação. }\end{array}$ & $\begin{array}{l}\text { Programa de } \\
\text { relacionamento } \\
\text { com o cliente } \\
\text { denominado } \\
\text { sugestão } \\
\text { premiada. } \\
\text { A área de } \\
\text { Engenharia } \\
\text { da empresa } \\
\text { cumpre } \\
\text { um papel } \\
\text { fundamental no } \\
\text { relacionamento } \\
\text { com o cliente. }\end{array}$ \\
\hline
\end{tabular}


possuem conhecimento técnico sobre o produto, pela sua experiência de uso e representam uma fonte potencial para contribuir com esse tipo de conhecimento no PDP. As empresas consideram que a IC melhora o relacionamento com os clientes. A empresa E considera que nesses relacionamentos se criam vínculos afetivos entre os clientes participantes e os representantes da empresa, o que suporta a lealdade desses clientes.

Os critérios utilizados para escolha de clientes, a serem envolvidos, diferenciam de empresa para empresa. Essa diferenciação se dá em função do tipo de segmento de mercado de atuação da empresa. As empresas B e D, do ramo de equipamentos médico-hospitalares, adotam critérios parecidos, mas se diferenciam na ordem de importância dos critérios. Assim, a empresa B considera mais importante "cliente formador de opinião"; já para a empresa D o critério mais importante é a "experiência técnica do cliente". A empresa E utiliza como critério de seleção o "usuário líder" e, segundo os entrevistados, a adoção deste critério já permitiu à empresa lançar uma nova linha de produtos ao mercado.

O tipo de interação entre a empresa e seus clientes ocorre de diferentes formas, sendo comuns as reuniões formais para testes e avaliação de protótipos. Outra forma de interação são as visitas técnicas que a

Quadro 5. Características da integração de clientes no PDP das empresas.

\begin{tabular}{|c|c|c|c|c|c|}
\hline & Empresa A & Empresa B & Empresa C & Empresa D & Empresa E \\
\hline $\begin{array}{l}\text { Fundamentos } \\
\text { para IC no } \\
\text { PDP }\end{array}$ & $\begin{array}{l}\text { Conhecimento } \\
\text { das necessidades } \\
\text { do mercado. }\end{array}$ & $\begin{array}{l}\text { Conhecimento } \\
\text { das necessidades } \\
\text { do mercado e } \\
\text { conhecimento } \\
\text { técnico. }\end{array}$ & $\begin{array}{l}\text { Conhecimento } \\
\text { das necessidades } \\
\text { do mercado e } \\
\text { conhecimento } \\
\text { técnico (embora } \\
\text { não seja } \\
\text { aproveitado pela } \\
\text { empresa). }\end{array}$ & $\begin{array}{l}\text { Conhecimento } \\
\text { das } \\
\text { necessidades } \\
\text { do mercado e } \\
\text { conhecimento } \\
\text { técnico. }\end{array}$ & $\begin{array}{c}\text { Conhecimento } \\
\text { das necessidades } \\
\text { do mercado e } \\
\text { conhecimento } \\
\text { técnico. } \\
\text { Manutenção } \\
\text { do bom } \\
\text { relacionamento } \\
\text { com os clientes }\end{array}$ \\
\hline $\begin{array}{l}\text { Critérios para } \\
\text { escolha de } \\
\text { clientes }\end{array}$ & $\begin{array}{c}\text { Parceiro para } \\
\text { observação; } \\
\text { alto potencial } \\
\text { de demanda; } \\
\text { competência para } \\
\text { testar o protótipo. }\end{array}$ & $\begin{array}{c}\text { Formador } \\
\text { de opinião; } \\
\text { experiência técnica; } \\
\text { disponibilidade } \\
\text { para integrar a } \\
\text { equipe de projeto, e } \\
\text { disponibilidade para } \\
\text { divulgar o produto. }\end{array}$ & $\begin{array}{l}\text { Clientes que } \\
\text { a empresa } \\
\text { perdeu para os } \\
\text { concorrentes; } \\
\text { e parceiros de } \\
\text { observação. }\end{array}$ & $\begin{array}{c}\text { Experiência } \\
\text { técnica; } \\
\text { formador } \\
\text { de opinião; } \\
\text { disponibilidade } \\
\text { para trabalhar } \\
\text { em projetos; e } \\
\text { disponibilidade } \\
\text { para divulgar o } \\
\text { produto. }\end{array}$ & $\begin{array}{l}\text { Usuário líder; } \\
\text { cliente com } \\
\text { alto poder } \\
\text { de demanda; } \\
\text { disponibilidade. }\end{array}$ \\
\hline $\begin{array}{c}\text { Tipos de } \\
\text { interação }\end{array}$ & $\begin{array}{l}\text { Reuniões formais; } \\
\text { observação } \\
\text { do cliente; } \\
\text { intercambio } \\
\text { de } e \text {-mails; } \\
\text { ensaios práticos } \\
\text { em conjunto; } \\
\text { participação } \\
\text { nos testes do } \\
\text { protótipo. }\end{array}$ & $\begin{array}{l}\text { Reuniões formais; } \\
\text { observação de } \\
\text { clientes; intercâmbio } \\
\text { de } e \text {-mails; visitas } \\
\text { técnicas aos clientes; } \\
\text { participação nos } \\
\text { testes do protótipo; } \\
\text { telefonemas; } \\
\text { videoconferência. }\end{array}$ & $\begin{array}{l}\text { Visitas técnicas } \\
\text { aos clientes; } \\
\text { intercâmbio } \\
\text { de } e \text {-mails e } \\
\text { telefonemas; } \\
\text { participação } \\
\text { nos testes do } \\
\text { protótipo; } \\
\text { videoconferência. }\end{array}$ & $\begin{array}{c}\text { Reuniões } \\
\text { formais; } \\
\text { intercâmbio } \\
\text { de } e \text {-mails; } \\
\text { ensaios práticos } \\
\text { em conjunto; } \\
\text { participação } \\
\text { nos testes do } \\
\text { protótipo; } \\
\text { reuniões } \\
\text { informais. }\end{array}$ & $\begin{array}{c}\text { Reuniões } \\
\text { formais; } \\
\text { observação } \\
\text { de clientes; } \\
\text { visitas técnicas } \\
\text { a clientes; } \\
\text { intercâmbio } \\
\text { de } e \text {-mails; } \\
\text { telefonemas; } \\
\text { interação online; } \\
\text { participação } \\
\text { nos testes do } \\
\text { protótipo. }\end{array}$ \\
\hline $\begin{array}{c}\text { Técnicas e } \\
\text { ferramentas } \\
\text { de apoio para } \\
\text { IC }\end{array}$ & $\begin{array}{c}\text { Folha de } \\
\text { verificação para } \\
\text { preencher as } \\
\text { necessidades dos } \\
\text { clientes e para } \\
\text { elaborar informes } \\
\text { de relatório de } \\
\text { teste da máquina. }\end{array}$ & $\begin{array}{l}\text { Folhas de } \\
\text { verificação; folhas } \\
\text { de registro segundo } \\
\text { recomendação da } \\
\text { ISO 13485:2003; } \\
\text { grupos focados. }\end{array}$ & $\begin{array}{c}\text { Formulários de } \\
\text { visita técnica. }\end{array}$ & $\begin{array}{c}\text { Folhas de } \\
\text { verificação; } \\
\text { folhas de } \\
\text { registro segundo } \\
\text { recomendação } \\
\text { da ISO } \\
\text { 13485:2003. } \\
\text { Grupos focados }\end{array}$ & $\begin{array}{l}\text { Folhas de } \\
\text { verificação; } \\
\text { Formulários de } \\
\text { visita técnica. } \\
\text { Portal de } \\
\text { sugestões na } \\
\text { internet. }\end{array}$ \\
\hline
\end{tabular}


empresa realiza aos seus clientes com o principal objetivo de conhecer suas necessidades reais.

A interação do cliente por meio da observação, citada por Nardi (1997), Leonard-Barton (1998) e Pancake (2005) como essencial quando se quer conhecer as reais necessidades dos clientes, é pouco explorada por essas empresas e, quando utilizada, por exemplo, nas empresas A e E, sua prática se resume ao preenchimento de relatório de visita de campo. Leonard-Barton (1998) cita um planejamento inicial para a observação, incluindo várias fontes de captação tais como equipamentos de gravação e de filmagem e um roteiro, atividades que não são praticadas nessas empresas.

A interação on-line com os clientes, praticada pela empresa E, se dá por meio de um portal da internet disponibilizado para a participação dos clientes, expondo ideias de novos produtos ou para melhorar as características de desempenho dos produtos existentes. A empresa B utiliza como meio de interação reuniões de videoconferência no desenvolvimento do projeto, especificamente na fase de seleção de soluções para o projeto. Já a empresa $\mathrm{C}$, utiliza também a videoconferência para acompanhamento do teste beta do protótipo no cliente parceiro. Esse tipo de interação, citada por Dahan e Hauseer (2002) e Kim, Bae e Kang (2008), como a mais viável economicamente, deveria ser mais utilizada pelas empresas.

As poucas ferramentas utilizadas por essas empresas para IC estão baseadas em modelos de documentos que se adequam aos critérios das normas ISO 9001:2010 e ISO 13485:2003, tais como folha de verificação e formulários de visita técnica. As folhas de verificação são utilizadas para acompanhamento dos testes de protótipos e os formulários de visita técnica para levantar necessidades dos clientes e registrar informações de interesse para o PDP. As empresas
B e D utilizam em parte o método de grupos focados em atividades de IC.

\subsection{Benefícios obtidos com a IC em projetos de desenvolvimento de produtos}

Os benefícios que as empresas alcançaram ao integrarem clientes nos seus PDPs são diversos, conforme mostra o Quadro 6. À exceção da empresa $\mathrm{C}$, o principal benefício declarado é a redução do nível de risco no lançamento do novo produto.

Considerando as definições de eficiência do projeto (alcançar o objetivo com os recursos planejados) e sua eficácia (desenvolver um produto que tenha sucesso no mercado), os benefícios citados pelas empresas fazem parte dessas duas medidas de desempenho do PDP.

No critério melhoria da eficiência do PDP, os benefícios citados contemplam: reduz os erros e as mudanças no projeto em desenvolvimento; permite conhecer com antecedência as especificações de qualidade do novo produto, permitindo melhorar a qualidade do PDP e do novo produto. No critério melhoria da eficácia do PDP, os benefícios contemplam: reduz o nível de risco associado ao lançamento do novo produto, aumenta a probabilidade de sucesso do produto ao servir de difusor na fase de seu lançamento, consegue transferir parte da responsabilidade da eficiência do produto (máquina e ou equipamento) para o cliente.

\section{Considerações e sugestões para gerenciar a integração de clientes no PDP}

As atividades de desenvolvimento de produto das empresas estudadas seguem um modelo próprio que auxilia a organização da equipe de desenvolvimento,

Quadro 6. Benefícios da IC em projetos de produtos.

\begin{tabular}{|c|c|}
\hline Empresa & Benefício da IC no PDP \\
\hline Empresa A & $\begin{array}{l}\text { Reduz o nível de risco associado ao lançamento do novo produto; impulsiona a inovação de } \\
\text { produtos e sua busca por novas soluções; aumenta o nível de desempenho do produto; e aumenta o } \\
\text { grau de parceria entre a empresa e seus clientes. }\end{array}$ \\
\hline Empresa B & $\begin{array}{l}\text { Reduz o risco e a incerteza do projeto; reduz os erros e mudanças do projeto; apresenta ideias para } \\
\text { inovação incremental e radical; aumenta a probabilidade de sucesso do produto ao servir de difusor } \\
\text { na fase de lançamento do produto. }\end{array}$ \\
\hline Empresa C & Apresenta ideias para inovação incremental. Apresenta informação de produtos concorrentes. \\
\hline Empresa D & $\begin{array}{l}\text { Reduz o risco associado ao lançamento do novo produto; impulsiona a inovação de produtos e a } \\
\text { busca por novas soluções; aumenta o nível de desempenho do produto; e aumenta a probabilidade } \\
\text { de sucesso do produto ao servir de difusor na fase de lançamento do produto. }\end{array}$ \\
\hline Empresa E & $\begin{array}{l}\text { Incentiva o desenvolvimento de um novo produto para um novo mercado; consegue transferir } \\
\text { parte da responsabilidade da eficiência do equipamento para o cliente; permite conhecer com } \\
\text { antecedência as especificações de qualidade do novo produto, contribuindo para melhorar a } \\
\text { qualidade do PDP e do novo produto. }\end{array}$ \\
\hline
\end{tabular}


planejamento das atividades do projeto, execução das atividades e a melhoria contínua, baseadas nos princípios da ISO9001: 2000 e adaptadas à realidade de cada uma das empresas.

A partir dos resultados da análise intercasos e da revisão bibliográfica, foram levantadas considerações, descritas abaixo, que devem ser levadas em conta para a prática da IC no PDP em empresas do setor de bens de capital.

$\mathrm{O}$ agrupamento dessas considerações deu-se em: Fundamentos para IC; Seleção de clientes; Interação; Técnicas de apoio; Benefícios para um projeto; e Organizacional; os quais representam importantes variáveis para análise e gestão da IC no PDP, conforme observado na revisão bibliográfica.

\subsection{Fundamentos para IC}

Foco na eficiência e na confiabilidade do processo produtivo do cliente. Esse foco é relevante em função da particularidade do produto (neste caso, máquina ou equipamento), uma vez que o equipamento desenvolvido irá influenciar o custo do processo produtivo do cliente.

Orientação da empresa aos clientes. Refere-se à abordagem estratégica da empresa, a qual determina que suas atividades e seus processos devem ter como ponto de partida as necessidades de seus clientes. Prahalad e Ramaswamy (2000) consideram que uma empresa com foco no cliente adota práticas de IC no PDP. No caso das empresas de bens de capital, cuja característica é o foco no cliente, essa orientação varia em intensidade. As empresas A, B, D e E podem ser consideradas com maior orientação para o mercado, enquanto a empresa $\mathrm{C}$, embora com planos futuros para melhorar essa orientação, apresenta menor intensidade em relação às demais.

Risco da integração do cliente. A empresa A considera que a IC no PDP pode gerar conflitos entre a empresa fabricante e os clientes participantes, particularmente quanto a uma possível obtenção de patentes. Entretanto, as empresas B, C, D e E, assim como Enkel, Perez-Freije e Gassmann (2005), consideram que esse risco pode ser reduzido pela definição clara das funções, responsabilidades e direitos do cliente, antes da sua participação no PDP.

Geração do conhecimento pela IC no PDP. A IC no PDP pode gerar conhecimentos para a empresa fabricante. Esse conhecimento pode ser em relação ao mercado e tecnológico.

\subsection{Seleção de clientes}

Perfil do cliente para o trabalho em equipe. Assim como os membros internos da equipe de projeto devem ter perfis para trabalhar em equipe, os clientes também devem ter essa característica. Recomenda-se levar em consideração esse fator na escolha do cliente.

Competência dos clientes. Competência relacionada à aptidão dos clientes no que diz respeito ao conhecimento sobre as necessidades de mercado e ao domínio técnico de uma tecnologia ou produto. Em alguns dos clientes esses conhecimentos podem estar implícitos ou tácitos.

Capacidade em infraestrutura do cliente. Na etapa de teste do protótipo, as máquinas e equipamentos em desenvolvimento precisam ser testados em ambiente real de trabalho e, para isso, a capacidade de produção do cliente, em termos de uma boa infraestrutura, facilita e reduz o risco de falha nos testes.

Tipo de projeto. A bibliografia sobre o tema, dentre elas, Callahan e Lasry (2004) e Lettl (2007) e todas as empresas estudadas consideram que o tipo de projeto, quanto ao grau de novidade do novo produto para o mercado e para a empresa, define o nível requerido de integração do cliente.

Critérios para seleção de clientes. Assim como citado na bibliografia sobre o tema, as empresas estudadas utilizam diversos critérios para escolher clientes para participarem do PDP, entre eles: necessidade do mercado (neste caso, máquinas e equipamentos para uso em processo de clientes industriais); ser formador de opinião; ter competência técnica; ter competência e conhecimento das necessidades do mercado, etc.

Papel do cliente. Definir o papel do cliente no PDP serve para evitar mal-entendidos entre a equipe da empresa e os clientes.

Qualidade de relacionamento entre a empresa e clientes (confiança). O relacionamento entre a empresa fabricante e seus clientes, mantido no tempo, gera confiança entre ambas as partes, que, por sua vez, influencia na escolha dos clientes a serem integrados no PDP. As empresas B e D adotam parcerias na condução de seus projetos de novos produtos e atualizam essa relação anualmente.

\subsection{Interação}

Processo iterativo. As atividades genéricas e repetitivas de Integração de Clientes - organizar, integrar e aprender - são necessárias para acompanhar o desenvolvimento do projeto no ciclo de atividades do PDP: construir, testar e melhorar.

Tipos de cooperação em IC. Os tipos de cooperação, de acordo com a participação do cliente, podem ser: fazer parte da equipe do projeto, cooperação ativa com alta frequência, cooperação ativa com baixa frequência, cooperação passiva com alta frequência e cooperação passiva com baixa frequência. Todas as empresas estudadas têm cooperação de seus clientes na realização e análise dos resultados do teste beta dos protótipos como parte da equipe do projeto. 
Nas outras fases ou atividades do desenvolvimento do produto, o tipo de cooperação varia de empresa para empresa.

Tipos de interação. A interação entre a empresa fabricante e seus clientes durante o PDP, conforme revisão bibliográfica e as práticas observadas no estudo de casos, pode se dar por meio de reuniões informais, reuniões formais, observações, conversações pelo telefone, e-mail, fax, etc.

Infraestrutura para suporte aos clientes. Ambientes físicos ou virtuais destinados à interação entre os clientes de uma mesma empresa podem ser adotados com a finalidade de facilitar o entendimento do novo produto e sua função, ou para adaptá-lo às necessidades do cliente. As empresas estudadas não dispõem dessa prática, entretanto, esta representa uma boa alternativa para integração de e entre clientes.

Relação de cooperação entre empresa e clientes. É o caso, por exemplo, da empresa A que mantém relações de cooperação por meio da disponibilização de seus laboratórios para seus clientes realizarem ensaios e testes dos novos produtos.

Perfil do líder do projeto. O líder do projeto, denominado na empresa Toyota de "Engenheiro Chefe", cumpre um papel fundamental na decisão e execução das práticas de IC durante o desenvolvimento do projeto. As empresas B e D consideram que uma característica importante do perfil desse líder é a facilidade de relacionamento com os clientes.

Perfil da equipe interna do projeto para IC. Destaca-se a relevância de se conhecer e acompanhar a cultura e comportamentos de trabalho dos funcionários da empresa, quando estes trabalham e interagem com os clientes, pois esses fatores influenciam a qualidade da interação e o desempenho do projeto.

\subsection{Técnicas de apoio}

Métodos e técnicas de apoio a IC. Apesar de quase todas as empresas estudadas não utilizarem métodos e técnicas específicos, a empresa $\mathrm{C}$ considera que há essa necessidade, e justifica sua baixa prática de IC pela falta de um método ou procedimento disponível na empresa.

Ferramentas de IC on-line. Refere-se a ferramentas apropriadas para a interação entre a empresa fabricante e os clientes. Pode incluir um software com livrarias (bases de dados) para montar novos produtos, grupos de componentes físicos de produtos, etc. Nambisan e Nambisan (2008) consideram eficientes os portais que as empresas disponibilizam para suas comunidades virtuais. Das empresas estudadas apenas a empresa E disponibiliza em seu portal uma ferramenta de IC com foco na busca por ideias de novos produtos ou para melhorar os produtos existentes.

\subsection{Benefícios para um projeto}

Nivel de incerteza do projeto. Este fator é consequente do grau de novidade e complexidade do produto em desenvolvimento, quanto maior a inovação do produto para o mercado maior é o nível de incerteza no PDP. A empresa E considera que a prática da IC, em projetos desenvolvidos por pedido, reduz a incerteza e a responsabilidade sobre o resultado do projeto é compartilhada entre a empresa e o cliente.

Razões para integrar clientes. Este fator está relacionado às vantagens da prática de envolver os clientes no PDP. As razões para esse envolvimento podem ser classificadas como sendo de nível estratégico e operacional. De ordem estratégica por reduzir incertezas do projeto do novo produto, e de ordem operacional por contribuir com informações de mercado e com informações técnicas para o desenvolvimento do novo produto.

Relação custo/benefício da integração de clientes. Relação entre o custo da integração do cliente e o nível de benefício obtido pelo novo produto lançado ao mercado. A empresa Shurter, citada no estudo de Kausch (2007), adota esse indicador para avaliar a prática de integração de clientes nos projetos de desenvolvimento.

\subsection{Organizacional}

Base de dados de clientes potenciais. A criação e a manutenção de uma base de dados de clientes permitem à empresa monitorar e selecionar clientes potenciais para integrar em seus projetos. Além disso, permitem uma forma de comunicação da empresa para com seus clientes, como no caso das práticas adotadas pelas empresas $\mathrm{B}$ e $\mathrm{D}$, que utilizam essas bases de dados para interagirem com seus clientes, fornecendo informações de interesse a grupos segmentados de clientes.

Barreiras às práticas de IC. Refere-se a fatores e variáveis que dificultam a prática da IC. Estas podem ser de ordem interna (por exemplo, falta de recursos para o projeto) ou externa (por exemplo, falta de profissionalismo dos clientes, falta de disponibilidade dos clientes, etc.)

Abordagem de processo para gestão da IC no PDP. Espera-se que as atividades de integração que são repetitivas sejam aperfeiçoadas ao longo do tempo. A visão de processo para esse grupo de atividades permite que ele seja aperfeiçoado.

Fases do PDP para integração de clientes. Um conjunto de atividades compõe uma fase e um grupo de fases compõe o PDP. A integração de clientes, citada em Kaulio (1998), Alam e Perry (2002) e Brockhoff (2003) e conforme observada no estudo de casos, pode ocorrer em todas as fases do PDP ou, de forma pontual, em atividades de algumas das 
fases. Devem-se avaliar as atividades e fases mais adequadas para ocorrer essa integração.

Formalizar as atividades de IC. Estabelecer procedimentos para a IC no PDP com o objetivo de aprimorar esta prática com o tempo. Também manter registros de documentos: contrato de cooperação, diretrizes e critérios de seleção, etc. com o objetivo de aprimorá-las com o tempo.

Serviço pós-venda. Serviços que a empresa fabricante disponibiliza para auxiliar o cliente no uso adequado do produto, bem como para manter o funcionamento do produto no processo do cliente. Todas as empresas estudadas oferecem esse serviço. A empresa $\mathrm{C}$ considera estratégico esse serviço e o realiza com seus próprios funcionários em todos os países de atuação.

\section{Considerações finais}

A tendência das empresas em procurarem focar seus processos de negócio na criação de valor para seus clientes, por meio do desenvolvimento de produtos, faz com que vejam seus clientes também como uma fonte de informação sobre necessidades de mercado e de outras competências. Essa realidade pode ser justificada pela mudança do papel do cliente no processo de negócio da empresa, passando de um espectador passivo para um participante ativo.

O setor industrial de bens de capital, quando comparado com outros setores, possui a particularidade que seus clientes têm como um dos principais fatores de decisão de compra: a confiabilidade do produto (máquina e ou equipamento) e o custo de operação desse produto. Esses fatores, em conjunto, definem em parte o custo do processo produtivo do cliente. Com isso, as empresas desse setor devem ou deveriam ter maior cuidado nas atividades de levantamento das necessidades reais dos clientes, especificamente procurando conhecer também como o novo produto irá se adequar e ajustar no processo produtivo do cliente.

A pesquisa de campo, realizada em dois momentos, ajudou a obter maior conhecimento sobre o tema. A pesquisa inicial, exploratória, realizada com duas empresas (A e B) permitiu conhecer práticas da IC e como esse tema era conduzido nessas empresas. No segundo momento, com a definição de uma melhor estrutura do roteiro de pesquisa e maior domínio conceitual sobre o tema, foi refeita a pesquisa nas duas empresas iniciais (A e B) e em outras três empresas (C, D e E).

As atividades de desenvolvimento de produto das empresas estudadas seguem um modelo geral que auxilia a organização da equipe, planejamento das atividades do projeto, execução das atividades e a melhoria contínua, com base nos princípios da ISO 9001:2000, do PMBOK e dos Princípios do Programa Seis Sigma, adaptados à realidade de cada uma das empresas. A empresa $\mathrm{D}$ é a que tem melhor estruturado o seu modelo e método para o PDP.
A prática de IC no PDP varia de empresa para empresa na sua configuração assim como no seu grau de intensidade. As empresas que possuem maiores atividades de IC são as que têm feito maiores investimentos em infraestrutura para essa finalidade. São os casos das empresas B e E.

As atividades de IC também são influenciadas pelos programas de relacionamento que as empresas mantêm com seus clientes. No caso da empresa A, a disponibilidade de seus laboratórios para atividades de pesquisa e testes rotineiros de seus clientes faz que seus clientes, beneficiados por essa política, tenham maior disponibilidade em participar de atividades de IC quando requisitadas pela empresa. As empresas $\mathrm{B}$ e $\mathrm{C}$, adotam um programa de relacionamento com os clientes médicos, desde o monitoramento de potenciais médicos clientes e seu papel como formador de opinião no mercado, assim como a realização de parcerias para criação e divulgação de novos produtos. A empresa $\mathrm{E}$ recorre ao uso da internet como meio de interação com seus clientes e usuários. A bibliografia internacional apresenta programas de relacionamento (DAHAN; HAUSER, 2002; ROWLEY; KUPIEC-TEAHAN; LEEMING, 2006; KIM; BAE; KANG, 2008), especialmente o uso de ferramentas virtuais, como sites de relacionamento monitorados pela empresa, como sendo efetivos e de baixo custo para essa prática.

As práticas de IC são consideradas, na bibliografia, de ordem estratégica para a empresa. Por meio da pesquisa de campo pode-se perceber que as empresas A, B e E são as que consideram essa prática de forma mais estratégica. Já as empresas $\mathrm{C}$ e D a consideram e a implementam com uma visão mais operacional do que estratégica.

Nos casos estudados, a integração de clientes ocorre com maior frequência nas fases iniciais do PDP, especificamente no levantamento de informações dos clientes e na fase de teste do protótipo, denominado de Teste Beta. Os fatores capacidade de infraestrutura do cliente e a parceria mantida com o fornecedor são decisivos para a seleção dos clientes participantes nessas atividades. A literatura internacional propõe o uso de métricas para selecionar clientes (SANDÉN, 2007), permitindo uma avaliação sistemática e a definição de diretrizes para as empresas estudadas.

As vantagens da IC nos projetos de desenvolvimento de produtos para as empresas, levantadas na bibliografia internacional, são reconhecidas pelas empresas estudadas na presente pesquisa. Entretanto, esse reconhecimento, na prática, não é devidamente traduzido em ações concretas. Essa constatação pode ser justificada pelo baixo grau de formalismo das atividades de IC, como, por exemplo, no reduzido uso de procedimentos; no estabelecimento reduzido de diretrizes, critérios e normas; no baixo uso de métodos, técnicas e ferramentas e; notadamente na 
quase inexistência de condições para o aprimoramento dessa prática pela acumulação de conhecimento. A literatura internacional apresenta essas técnicas e procedimentos implementados em algumas empresas multinacionais: Hilti (KAUSCH, 2007); Procter \& Gamble (HUSTON; SAKKAB, 2006) e; 3M (LILIEN et al., 2002).

A falta de conhecimento e o baixo uso de procedimentos, métodos e técnicas de apoio a atividades de IC fazem com que essa prática seja pouco aproveitada pelas empresas, conforme citado pela empresa $\mathrm{C}$, que reconhece em alguns de seus clientes fontes potenciais para participar em projetos de novos produtos, pelo domínio técnico e pelo perfil inovador. Entretanto, por falta de procedimento e regulamentação, essas oportunidades ainda não foram devidamente aproveitadas.

Uma prática utilizada pela empresa A e não encontrada na literatura internacional é a disponibilização gratuita de seus laboratórios para uso de testes de produtos de seus clientes. Essa realidade ajudou a ter meios para captar as necessidades de seus clientes, bem como possibilitou um relacionamento de parceria que favorece a compatibilidade entre as necessidades dos clientes e as soluções desenvolvidas, descritas por Von Hippel (2005) como fundamental para uma inovação de sucesso no processo e no resultado.

A prática de IC no PDP das empresas estudadas requer maiores atividades quando comparadas com empresas localizadas em países desenvolvidos, na sistematização de suas práticas, assim como no uso de ferramentas e procedimentos. Essa constatação também pode ser verificada no relatório da OCDE sobre práticas de open innovation (ORGANISATION..., 2008) em que se verificou que atividades de inovação, realizadas em parceria entre a empresa e seus clientes, são mais intensas em países mais desenvolvidos economicamente e socialmente, como são os casos da Finlândia, Alemanha, Reino Unido e Irlanda. As considerações para a prática de IC no PDP levantadas na pesquisa bibliográfica e no estudo de casos, descritas no item 5 deste artigo, são diretrizes que poderiam ser consideradas pelas empresas que buscam: ter foco nas necessidades dos clientes e como consequência reduzir os riscos de mercado no lançamento de novos produtos, o que, por sua vez, melhora a eficiência e eficácia do PDP.

Para futuros estudos sobre o tema, recomenda-se discutir e propor um modelo de processo para operacionalização e gestão da IC no PDP com procedimentos, atividades, métodos e ferramentas e que sirva de referência para as empresas gerenciarem essa integração.

\section{Referências}

ALAM, I. Interacting with customers in the new product development process. In: KAHN, K. B. The PMDA handbook of new product development. 2 nd ed. New Jersey: John Wiley \& Sons Inc., 2005. p. 249-262.

ALAM, I.; PERRY, A. A customer-oriented new service development. Journal of Service Marketing, v. 16, n. 2, p. 515-534, 2002. http://dx.doi. org/10.1108/08876040210443391

BECKER, W.; PETERS, J. R\&D-competition between vertical corporate networks: Market structure and strategic R\&D-spillovers. Economics of Innovation \& New Technology, v. 6, n.1, p. 51-71, 1998. http:// dx.doi.org/10.1080/10438599800000013

BLACKBOURN, J. D.; SCUDDER, G. D.; VAN WASSENHOVE, L. N. Concurrent software development: resolving the time and productivity paradoxes. Communications of the ACM, 2000.

BONNER, J. M.; WALKER, O. Selecting influential Business-to-Business customers in new product development: relational embeddedness and knowledge heterogeneity considerations. The Journal of Product Innovation Management, v. 4, n. 21, p. 155-169, 2004. http://dx.doi.org/10.1111/j.0737-6782.2004.00067.x

BROCKHOFF, K. Customers' perspectives of involvement in new product development. International Journal of Technology Management, v. 26, n. 5-6, p. 464-481, 2003. http://dx.doi.org/10.1504/IJTM.2003.003418

BUUR, J.; MATTHEUS, B. Participatory Innovation. International Journal of Innovation Management, v. 12, n. 3, p. 255-273, 2008. http://dx.doi.org/10.1142/ S1363919608001996

CALLAHAN, J.; LASRY, E. The importance of customer in the development of very new products. R\&D Management, v. 34, n. 2, p.107-120, 2004. http:// dx.doi.org/10.1111/j.1467-9310.2004.00327.x

CHEN, C.; YAN, W. An in-process customer utility prediction system for product conceptualization. Expert System with Applications, v. 34, n. 4, p. 2555-2567, 2008. http://dx.doi.org/10.1016/j.eswa.2007.04.019

CHRISTENSEN, C. M.; RAYNOR, M. E. The innovator's solution: creating and sustaining successful growth. Boston: Harvard Business School Press, 2003.

COOPER, R. G. Formula for Success in New Product Development: The seven principles of the latest StageGate $^{\circledR}$ method. 2007. Disponível em: <http://www. stage-gate.net/downloads/working_papers/wp_23.pdf>. Acesso em: 11 abr. 2008.

COOPER, R. G. Winning at new products: Accelerating the process from idea to launch. Reading: Perseus Books, 2001.

COOPER, R. New products - What separates the winners from the losers and what drive success. In: KAHN, K. The PMDA handbook of new product development. 2nd ed. New Jersey: John Wiley \& Sons Inc., 2005. p. 3-28.

DAHAN, E.; HAUSER, J. R. The virtual customer. The Journal of Product Innovation Management, v. 19, p. 332-353, 2002. http://dx.doi.org/10.1016/ S0737-6782(02)00151-0

DESCHAMPS, J. P.; NAYAK, P. R. Produtos irresistíveis. Rio de Janeiro: Makron Books, 1997.

DRUCKER, P. The discipline of innovation. In: HARVARD Business Review: The innovative enterprise. Boston: Harvard Business School Press, 2002. p.95-102. 
EDVARDSSON, B. et al. Involving customer in new service development. Sweden: Imperial College Press, 2006.

EISENHARDT, K. M.; GRAEBNER, M. Theory building from cases: opportunities and challenges. Academy of Management Journal, v. 50, n. 1, p. 25-32, 2007. http:// dx.doi.org/10.5465/AMJ.2007.24160888

ENKEL, E.; KAUSCH, C.; GASSMANN, O. Managing the Risk of Customer Integration. European Management Journal, v. 23, n. 2, p. 203-213, 2005. http://dx.doi. org/10.1016/j.emj.2005.02.005

ENKEL, E.; PEREZ-FREIJE, J.; GASSMANN, O. Minimizing market risks through customer integration in new product development: Learning from bad practice. Journal Compilation, v. 14, n. 4, 2005.

FRANKE, N.; KEINZ, P.; SCHREIER, M. Complementing mass customization toolkits with user communities: how peer input improves customer self-design. The Journal of Product Innovation Management, v. 25, p. 546-559, 2008. http://dx.doi. org/10.1111/j.1540-5885.2008.00321.x

FRANKE, N.; PILLER, F. Value creating by toolkits for user innovation and design: The case of the watch market. The Journal of Product Innovation Management, v. 21, p. 401-415, 2004. http://dx.doi. org/10.1111/j.0737-6782.2004.00094.x

GALES, L.; MASOUR-COLE, D. User involvement in innovations projects: toward an information processing model. Journal of Engineering and Technology Management, v. 12, p. 77-109, 1995. http://dx.doi. org/10.1016/0923-4748(95)00005-7

GONZÁLEZ, M. O.; TOLEDO, J. C. A integração do cliente no processo de desenvolvimento de produto: revisão bibliográfica sistemática e temas para pesquisa. Revista Produção, v. 22, n. 1, p. 14-26, 2012.

GONZÁLEZ, M. O. Processo para gerenciar a integração de clientes no processo de desenvolvimento de produtos. 2010. 242 f. Tese (Doutorado em Engenharia de Produção)-Universidade Federal de São Carlos, São Carlos, Brasil, 2010.

GONZÁLEZ, M. O. et al. O envolvimento do cliente no processo de desenvolvimento de produtos: estudo de casos no setor de equipamentos médicohospitalares. In: SIMPÓSIO DE ENGENHARIA DE PRODUÇÃO - SIMPEP, 15., 2008, Bauru. Anais... Bauru, 2008.

GRIFFIN, A. Obtaining customers need for product development. In: KAHN, K. B. The PMDA handbook of new product development. 2nd ed. New Jersey: John Wiley \& Sons Inc., 2005. p. 211-227.

GRIFFIN, A.; HAUSER, J. R. The voice of the customer. Marketing Science, v. 12, n. 1, p. 1-27, 1993. http:// dx.doi.org/10.1287/mksc.12.1.1

GRIFFIN, A. et al. Voices from the Field: How Exceptional Industrial Innovators Innovate. Journal of Product Innovation Management, v. 26, n. 2, p. 222-240, 2009. http://dx.doi.org/10.1111/j.1540-5885.2009.00347.x

GRUNER, K. E.; HOMBURG C. Does Customer Interaction Enhance New Product Success? Journal of Business Research, v. 49, p. 1-14, 2000. http://dx.doi.org/10.1016/ S0148-2963(99)00013-2
GUPTA, A. K.; WILEMON, D. L. Changing Patterns in Industrial R\&D Management. Journal of Product and Innovation Management, v. 13, p. 497-511, 1996. http://dx.doi.org/10.1016/S0737-6782(96)00051-3

HEISKANEN, E. et al. User involvement in radical innovation: are consumers conservative? European Journal of Innovation Management, v. 10, n. 4, p. 489-509, 2007. http://dx.doi.org/10.1108/14601060710828790

HUSTON, L.; SAKKAB, N. Connect and develop: inside Procter \& Gamble's new model for innovation. Harvard Business Review, v. 84, n. 3, 2006.

INSTITUTO BRASILEIRO DE GEOGRAFIA E ESTATÍSTICA - IBGE. Pesquisa Industrial de Inovação Tecnológica - PINTEC 2003-2005. Análise dos Resultados. Rio de Janeiro: IBGE, 2007.

INSTITUTO BRASILEIRO DE GEOGRAFIA E ESTATÍSTICA - IBGE. Pesquisa Industrial de Inovação Tecnológica - PINTEC 2006-2008. Análise dos Resultados. Rio de Janeiro: IBGE, 2010.

JANSSEN, K. L.; DANKBAAR, B. Proactive involvement of consumers in innovation: selecting appropriate techniques. International Journal of Innovation Management, v. 12, p. 511-541, 2008. http://dx.doi. org/10.1142/S1363919608002047

JEPPESEN, L. B. User Toolkits for Innovation: Consumers Support Each Other. The Journal of Product Innovation Management, v. 22, p. 347-362, 2005. http://dx.doi. org/10.1111/j.0737-6782.2005.00131.x

KAHN, K. PDMA: Handbook of new product development. New Jersey: John Wiley, 2005.

KAULIO, M. A. Customer, consumer and user involvement in new product development: a framework and a review of selected methods. Total Quality Management, v. 9, n. 1, p. 141-149, 1998. http://dx.doi. org/10.1080/0954412989333

KAUSCH, C. A Risk-Benefit Perspective on Early Customer Integration. Switzerland: Physica-Verlag Heidelberg, 2007.

KIM, J. H.; BAE, Z.; KANG, S. The role of online brand community in new product development: case studies on digital product manufacturers in korea. International Journal of Innovation Management, v. 12, n. 3, p. 357-376, 2008. http://dx.doi.org/10.1142/ S1363919608002011

KOTLER, P. Administração de Marketing. 10th ed. São Paulo: Prentice Hall, 2000.

KRISTENSSON, P.; GUSTAFSSON, A.; ARCHER, T. Harnessing the creative potential among users. The Journal of Product Innovation Management, v. 21, p. 4-14, 2004. http://dx.doi. org/10.1111/j.0737-6782.2004.00050.x

KUJALA, S. User involvement: a review of the benefits and challenges. Behaviour \& Information Technology, v. 22, n. 1, p. 1-16, 2003. http://dx.doi. org/10.1080/01449290301782

LAGROSEN, S. Customer involvement in new product development: A relationship marketing perspective. European Journal of Innovation Management, v. 8 , n. 4, p. 424-436, 2005. http://dx.doi. org/10.1108/14601060510627803 
LAU, A. K. W.; YAM, R. C. M.; TAN, E. P. Y. Supply Chain Product Co-development, product modularity and product performance. Industrial Management \& Data System, v. 107, n. 7, p. 1036- 1065, 2007. http:// dx.doi.org/10.1108/02635570710816739

LEONARD-BARTON, D. Nascentes do Saber. Rio de Janeiro: Fundação Getulio Vargas, 1998.

LETTL, C. User involvement competence for radical innovation. Journal of Engineering and Technology Management, v. 24, p. 53-75, 2007. http://dx.doi. org/10.1016/j.jengtecman.2007.01.004

LILIEN, G. L. et al. Performance assessment of the Lead User idea-generation process for new product development. Management Science, v. 48, n. 8, p. 1042-1059, 2002. http://dx.doi.org/10.1287/mnsc.48.8.1042.171

MAGNUSSON, P. R. Benefits of involving users in service innovation. European Journal of Innovation Management, v. 6, n. 4, p. 228-238, 2003. http://dx.doi. org/10.1108/14601060310500940

MASCARENHAS, O.; KESAVAN, R.; BERNACCHI, M. Customer value-chain involvement for co-creating customer delight, Journal of Consumer Marketing, v. 21, n. 7, p. 486-496, 2004. http://dx.doi. org/10.1108/07363760410568707

MATTHING, J.; SANDÉN, B.; EDVARDSSON B. New service development: learning from and with customers. International Journal of Service Industry Management, v. 15, n. 5, p. 479-498, 2004. http:// dx.doi.org/10.1108/09564230410564948

MORGAN, J. M.; LIKER, J. K. The Toyota product development system: integrating people, process, and technology. New York: Productivity Press, 2006.

NAMBISAN, S.; NAMBISAN, P. How to profit from a better virtual customer environment. MIT Sloan Management Review, v. 49, n. 3, p. 53-61, 2008.

NARDI, B. The use of ethnographic methods in design and evaluation. In: HELANDER, M. G.; LANDAUER, T. K.; PRABHU, P. (Eds.). Handbook of Human-Computer Interaction. North-Holland: Elsevier Science, 1997. p. 361-366.

ORGANISATION FOR ECONOMIC CO-OPERATION AND DEVELOPMENT - OCDE. Open innovation in global networks. Relatório ISBN 978-92-6404767-9. 2008, 127 p.

OZER, M. Process Implications of the Use of the Internet in New Product Development: A Conceptual Analysis. Industrial Marketing Management, v. 32, n. 6, p. 517-530, 2003. http://dx.doi.org/10.1016/ S0019-8501(02)00276-6

PAGE, A. L. Assessing new product development practices and performance establishing crucial norms. The Journal of Product Innovation Management, v. 10, p. 273-90, 1993. http://dx.doi. org/10.1016/0737-6782(93)90071-W

PALS, N. et al. Three approaches to take the user perspective into account during new product design. International Journal of Innovation Management, v. 12, n. 3, p. 275-294, 2008. http://dx.doi.org/10.1142/ S1363919608002023

PANCAKE, M. H. Human factors engineering considerations in new product development. In: KAHN, K. B. The
PMDA handbook of new product development. 2nd ed. New Jersey: John Wiley \& Sons Inc., 2005. p. 406-416.

PRAHALAD, C. K.; RAMASWAMY, V. Co-opting customer competence. Harvard Business Review, v. 78, p. 79-87, 2000

RAASH, C.; HERSTATT, C.; LOOCK, P. The dynamics of user innovation: drivers and impediments of innovation activities. International Journal of Innovation Management, v. 12, n. 3, p. 377-398, 2008. http:// dx.doi.org/10.1142/S1363919608002060

ROWLEY, J.; KUPIEC-TEAHAN, B.; LEEMING, E. Customer community and co-creating: a case study. Marketing Intelligence \& Planning, v. 25, n. 2, p. 136-146, 2007. http://dx.doi. org/10.1108/02634500710737924

ROZENFELD, H. et al. Gestão de Desenvolvimento de Produtos: uma referência para a melhoria do processo. São Paulo: Saraiva, 2006. 542 p.

SANDÉN, B. The customer's role in new service development. 2007. 207 f. Tese (Doctor of Management)Faculty of Economic Sciences, Communication and IT Business Administration, Karlstad University, 2007.

SCHREIER, M.; PRUGL, R. Extending lead user theory: antecedents and consequences consumers lead-userness. The Journal of Product Innovation Management, v. 25, p. 331-346, 2008. http://dx.doi. org/10.1111/j.1540-5885.2008.00305.x

SHAH, S. G. S.; ROBINSON, I. Benefits of and barriers to involving user in medical device technology development and evaluation. International Journal of Technology Assessment in Health Care, v. 23, n. 1, p. 131-137, 2007. http://dx.doi.org/10.1017/S0266462307051677

SHAH, S. G. S; ROBINSON, I. User involvement in healthcare technology development and assessment. International Journal of Health Care Quality Assurance, v. 19, n. 6, p. 500-515, 2006. http://dx.doi. org/10.1108/09526860610687619

STEVENS, G. A.; BURLEY, J. Piloting the rocket of radical innovation. Research Technology Management, v. 46, n. 2, p. $16-25,2003$.

ULRICH, K. T.; EPPINGER, S. D. Product design and development. 4th ed. New York: McGraw Hill, 2008. 263 p.

VON HIPPEL, E. Democratizing Innovation. Cambridge: MIT Press, 2005.

VON HIPPEL, E. Lead Users: A source of novel product concepts. Management Science, v. 32, n. 7, p. 791-805, 1986. http://dx.doi.org/10.1287/ mnsc.32.7.791

VON HIPPEL, E. Perspective: user toolkits for innovation. The Journal of Product Innovation Management, v. 18, p. 247-257, 2001. http://dx.doi.org/10.1016/ S0737-6782(01)00090-X

VON HIPPEL, E.; KATZ, R. Shifting innovation to users via toolkits. Management Science, v. 48, n. 7, p. 821-833, 2002. http://dx.doi.org/10.1287/ mnsc.48.7.821.2817

YIN, R. K. Estudo de Caso: Planejamento e Métodos. 2. ed. Porto Alegre: Bookman, 2001. 
Apêndice 1. Roteiro da pesquisa de campo.

\section{Introdução}

O objetivo desta pesquisa é investigar variáveis presentes na prática da Integração de Clientes no Processo de Desenvolvimento de Produto em empresas de bens de capital.

- Para consecução da pesquisa deve-se entrevistar os seguintes profissionais;

- Gerente administrativo e/ou Gerente de Marketing;

- Gerente de P\&D e/ou de PDP e/ou de Engenharia; e

- Gerente de Serviços pós-venda e/ou Gerente da Qualidade.

As entrevistas podem ser realizadas num único dia, sendo que o tempo médio de entrevista com cada pessoa é de uma hora a uma hora e meia.

O foco da entrevista é sobre os aspectos relacionados à: fatores estratégicos da empresa relacionados ao seu mercado, gestão do processo de desenvolvimento de produto, a integração de clientes no processo de desenvolvimento de produto e nos fatores que influenciam integração do cliente no desenvolvimento de produto.

\section{Procedimento}

Preferencialmente as pessoas devem ser entrevistadas na seguinte ordem:

- Gerente administrativo e/ou Gerente de Marketing;

- Gerente de P\&D e/ou de PDP e/ou de Engenharia; e

- Gerente de Serviços pós-venda e/ou Gerente da Qualidade.

A ordem acima pode sofrer alterações conforme as circunstancias.

Sempre que possível recomenda-se entrevistar as pessoas de forma separada para que não ocorra nenhum tipo de inibição entre elas.

O objetivo da pesquisa juntamente com os tópicos serão apresentados aos entrevistados e estes poderão discorrer sobre o assunto para que vieses não sejam adicionados no levantamento de dados e nos resultados da pesquisa.

O pesquisador, com base no roteiro de entrevista dará início ao processo de entrevista. Destacando-se ser aconselhável gravar as entrevistas, quando permitido.

Anotações serão efetuadas durante as entrevistas.

Quando necessário poderão ser solicitados por documentos que possam comprovar ou elucidar elementos considerados importantes.

$\mathrm{O}$ pesquisador precisa ficar atento para fatos relacionados ao objetivo da pesquisa durante a visita à planta da empresa.
Ao fechamento dos tópicos, os assuntos que não foram contemplados ou que surgiram no caso poderão ser explorados pelo pesquisador.

Os materiais utilizados serão: roteiros de entrevista, cópia dos roteiros de entrevista para os entrevistados, formulário para coleta de dados e gravador.

\section{Tópicos da entrevista}

\section{Primeira parte:}

1. Dados funcionais dos entrevistados (Conhecido antes da entrevista e confirmar no início da entrevista)

\section{Segunda parte:}

\subsection{Caracterização da empresa}

- Tipo de processo de produção.

- Programas e certificações.

\subsection{Orientação estratégica da empresa}

- Critério competitivo da empresa.

- Valor de faturamento de venda de produtos e serviço pós-venda.

\subsection{Características dos clientes da empresa}

- Quantidade de clientes da empresa. Características peculiares dos clientes.

- Nível de rotatividade de clientes, índice de satisfação e fidelidade de clientes.

\subsection{Estratégia de relacionamento com os clientes}

- Atividades de marketing de relacionamento.

- Organização do setor de serviços aos clientes.

\section{Terceira parte:}

\subsection{Estratégia da área de $\mathrm{P} \& \mathrm{D} / \mathrm{DP} /$ Engenharia da empresa (objetivos de desempenho)}

\subsection{Gestão de desenvolvimento de produtos}

- Função de área de P\&D/DP/Engenharia dentro da empresa;

- Número e grau de instrução de funcionários em P\&D/DP/Engenharia;

- Tipos de projetos em P\&D/DP/Engenharia;

- Organização e gerenciamento de projeto de novos produtos; 
- Fontes de ideias para o desenvolvimento de novos produtos;

- Modelo de gestão processo de desenvolvimento de produtos; e

- Desenvolvimento de novo serviço como complemento do novo produto.

\subsection{Gestão e práticas da Integração} de Clientes no processo de desenvolvimento de produtos

- Competências dos clientes para inovação de novos produtos ou serviços;
- Atividades de interação entre a empresa e seus clientes;

- Critério de escolha de clientes para sua integração;

- Técnicas e ferramentas de apoio para a prática da integração de clientes;

- Competência da empresa fabricante para lidar com a integração de clientes;

- Benefícios da integração de clientes no PDP;

- Desvantagens da integração de clientes; e

- Passado, presente e futuro da prática da integração de clientes no PDP da empresa. 